\title{
Cervical cancer screening program based on HPV testing and conventional Papanicolaou cytology for jail inmates
}

\author{
Vincenza Fabiano ${ }^{1}$, Luciano Mariani ${ }^{2}$, Maria Rosaria Giovagnoli ${ }^{1}$, Salvatore Raffa ${ }^{1}$, Cristina \\ Vincenzoni ${ }^{2}$, Fausto de Michetti ${ }^{3}$, Francesco Bevere ${ }^{4}$, Deborah French ${ }^{1 *}$ \\ ${ }^{1}$ Department Clinical and Molecular Medicine, "Sapienza” University of Rome, S. Andrea Hospital, Rome, Italy; \\ ${ }^{*}$ Corresponding Author: deborah.french@uniroma1.it \\ ${ }^{2}$ Department of Gynaecology, Regina Elena National Cancer Institute of Rome, Rome, Italy \\ ${ }^{3}$ Medical Service, Female Jail "Rebibbia" of Rome, Rome, Italy \\ ${ }^{4}$ General Direction, Regina Elena National Cancer Institute of Rome, Rome, Italy
}

Received 7 May 2010; revised 17 June 2010; accepted 20 June 2010.

\section{ABSTRACT}

Background: To assess the validity of Human Papillomavirus (HPV) testing in a group of women at high risk for developing cervical cancer, a screening intervention was applied to a population of jail inmates in Rome, Italy. This cross-sectional study provided also new insights on the risk factors and on the HPV genotype distribution. Methods: We have invited 350 inmates to the preliminary stage of the screening program and 98 inmates decided to participate to the study and filled out a questionnaire for the history of attendance to previous cervical screening and for the known risk factors for cervical malignancies. HPV DNA test, conventional Pap smear and HPV genotyping were performed. Results: The percentage of women with High Risk (HR) HPV positivity were $19.3 \%$. The inmates with LSIL/ HSIL status showed a significantly higher prevalence of HR-HPV positivity $(100 \%$ vs. $16.3 \%$; $p<0.001)$ and of multiple HPV types $(60 \%$ vs. $1.2 \% ; p<0.001)$ compared to women with normal/ASCUS Pap smear. HPV16 was the predominant genotype in either single or multiple infections. Conclusions: The results indicated that HPV DNA-based approach is a strategy useful for incarcerated women which do not have the opportunity or the social and cultural environment to receive preventive care.

Keywords: Cervical Cancer Screening; HPV; Inmates

\section{BACKGROUND}

During the last few years, cervical cancer screening programs for women in prison have been carried out in the United States and in Canada [1-5]. Although the results of such preventive care interventions are still not complete and require further work and follow-up, these studies have pointed out the interesting profile of a jail inmate population as an high risk group for developing cervical malignancies. In fact, several socio-demographic risk factors including race/ethnicity, lower level of education and drug or alcohol abuse are responsible for the higher incidence rates of cancer in prisoner women $[6,7]$.

Human papillomaviruses (HPVs) of the high risk types are known to play a causative role in cervical cancerogenesis [2]. HPV infection is correlated primarily with the number of sex partners, but is positively associated also with smoking and oral contraceptive use [8-10].

A number of randomized controlled trials have recently shown that HPV testing for cervical cancer screening shows a higher sensitivity compared with the conventional Papanicolaou cytology [11-13].

These studies have indicated that the prevalence of HPV infection in the general population is strictly related to the age of the women attending the screening [14], with a peak incidence of HPV infection occurring at the age of 16-20, as well as to their socioeconomic status [6].

With the aim to contribute to the assessment of the validity of the HPV DNA testing for cervical cancer screening and to increase the knowledge of the role of the risk factors and on the distribution of the HPV types, we have conducted a preventive care program by parallel HPV DNA test and conventional cytology on a popula- 
tion of women prisoners in the "Rebibbia" Female Jail of Rome.

\section{METHODS}

This cross-sectional study was approved by the Second Faculty of Medicine of "Sapienza" University of Rome, by the Regina Elena National Cancer Institute of Rome and by the "Rebibbia" Female Jail of Rome. The protocol was designated following the recommended guidelines of the following italian scientific societies: SICPCV (Italian Society of Colposcopy and Cervico-Vaginal Pathology) and GISCI (Italian Group of Cervical Cancer Screening), adapted in accordance with the experimental arm of the New Technologies for Cervical Cancer (NTCC) [12].

\subsection{Procedure and Questionnaire}

In the preliminary stage of our study, to invite the inmates to participate to the screening program we first organised three sequential meetings in the prison theatre in order to describe the value of cervical cancer screening, the role of the HPV infection and the routes of viral transmission. To explain the aims of the program and the procedure of the gynecological control we used slides with cartoons and figures to favour the comprehension from a multi ethnical population.

98 out of 350 inmate women decided to participate to the study and filled out a questionnaire by themselves. The questionnaire was written in italian and was translated into English and Spanish. The questions included those required for the history of attendance to previous cervical screening as well as the willingness to be screened in the prison setting and those for the known risk factors for cervical malignancies such as smoke, drug/alcohol and sexual behaviour (Table 1). Written informed consent was obtained from all participants.

\subsection{Specimen Collection}

The women then underwent a gynecological examination including three different cervical samples: 1) a sample of cervical cells taken by Cervical sampler, (Digene Corporation, Gaitesburg, MD) and collect in standard transport medium for HPV DNA test; 2) an eso-endocervical scraping for conventional Pap Test; 3) a sample of cervical cells taken by Ayre's Spatula and Cytobrush (Cytobrush DOC, Gardening, Genova, Italy) and collect in Transport buffer for HPV DNA genotyping.

\subsection{HPV Detection}

HPV DNA test was performed by Hybrid Capture II hybridization assay (HC2 Digene Corporation, Gaith-
Table 1. Questions for the inmates enrolled into the screening program.

\begin{tabular}{l}
\hline Characteristics \\
\hline Patient Code \\
Age \\
Race/ethnicity (White, Latino/Hispanic, African, other) \\
Marital Status (Unmarried without current male partner, unmarried \\
with current male partner, married, widowed, separed-divorced) \\
Questions \\
\hline How many sexual partners did you have in your life? \\
Which was the age of your first sexual intercourse? \\
Did you never practice oral sex? \\
Did you never practice anal sex? \\
Do you smoke? If yes, how many cigarettes/day? \\
Do you drink? If yes, how much? \\
Do you use contraceptive methods? If yes, you use condom? \\
Do you have carried out a PAP smear during the last three years?
\end{tabular}

ersburg, Maryland USA), according to the manufacturer's instructions. HC2 test, was used with the "highrisk" probes designed to detect HPV types 16, 18, 31, 33, $35,39,45,51,52,56,58,59,68$ positivity. A cervical smear was prepared for conventional Pap test and classified according to the Bethesda System 2001.

HPV genotyping test was performed using a line probe assay for all cervical samples which were positive at the $\mathrm{HC} 2$ test. Total DNA was extracted QIAamp ${ }^{\circledR}$ DNA extraction (Qiagen, Hilden, Germany) and appropriate spin columns according to the manufacturer's protocol. The INNO-LiPA HPV Genotyping Extra is a line probe assay designed for the identification of 28 different genotypes of the Human Papillomavirus by detection of specific sequences in the L1 region of the HPV genome. INNO-LiPA identified HPV types 6,11 , $16,18,31,33,35,39,40,42,43,44,45,51,52,53,54$, 56, 58, 59, 66, 68, 70, 74 (INNO-LiPA; Innogenetics Gent, Belgium).

\subsection{Cytological and Histological Diagnosis}

All the lesions cytologically diagnosed, underwent colposcopic evaluation. The high grade lesions were immediately treated, excisional procedures were performed by a loop electrosurgical excisional procedure (LEEP), or traditional cone-biopsy, in the day surgery of Regina Elena National Cancer Institute of Rome. The histological diagnosis for all treated cases was CIN III according with cytology and colposcopic examination. 


\subsection{Statistical Methods}

Logistic regression analysis was performed to model the association between sociodemographic characteristics, sexual and health behaviours and human papillomavirus (HPV) status or cervical cytology data. Odds Ratios (ORs) was calculated for each potential risk factors. Chi square and Fisher's exact test was used to compare categorical variables and a $\mathrm{P}$ for trend was calculated for ordinal categories.

\section{RESULTS}

As shown in Table 2, the epidemiological characteristics of the jail inmates corresponded to those described for a high risk population to develop cervical cancer. The sexual behaviour of the inmate group was also at higher risk because of the increased number of partners and the earlier sex intercourse. In fact, the logistic regression analysis showed that the OR for HR-HPV positivity was significantly associated with lifetime number of sex partners $(\mathrm{OR}=2.00$ for $5-9$ partners; $\mathrm{OR}=13.3$ for $>10$ partners; $p=0.036)$.

Cervical samples from the 98 inmate participants to the screening were analyzed by HPV DNA test using the Hybrid Capture 2 hybridization assay to detect HR-HPV positivity and by conventional cytology. As shown in Table 3, the inmates with LSIL/HSIL status showed a significantly higher prevalence of HR-HPV positivity $(100 \%$ vs. $16.3 \%$; $<<0.001)$. In addition, the percentage of subjects positive for both HPV DNA testing and cytology was comparable to that reported in other screening programs $[12,15]$, although a high prevalence of high grade pre-neoplastic lesions (HSIL/LSIL) was found among the inmates (Table 2). However, the superior sensitivity of the HPV testing compared to cytology was shown by the high percentage of cases positive for HPV DNA but negative at the cytological exam (14.3\%) in agreement with several recent studies and new guidelines for cervical cancer prevention $[15,16]$. The OR for LSIL/HSIL status was significantly associated with the lifetime number of sex partners $(\mathrm{OR}=1.8$ for $5-9$ partners; $O R=4.1$ for $>10$ partners; $p=0.033)$ and for the age of first sexual intercourse $(\mathrm{OR}=2.0$ for age $<15$ years; $p<0.05)$ but not for none Pap smear performed during the past 3 years $(\mathrm{OR}=0.8 ; \mathrm{p}=0.78)$.

Regard to the distribution of the HR-HPV types in the high risk inmate group and the amount of single and multiple infections, the genotyping assay on the $19 \mathrm{HPV}$ DNA positive samples showed the much higher prevalence of HPV16 compared to the other types in either single or multiple infections (total HPV16 prevalence: $65 \%$; single prevalence: $35 \%$; multiple prevalence: $30 \%$;

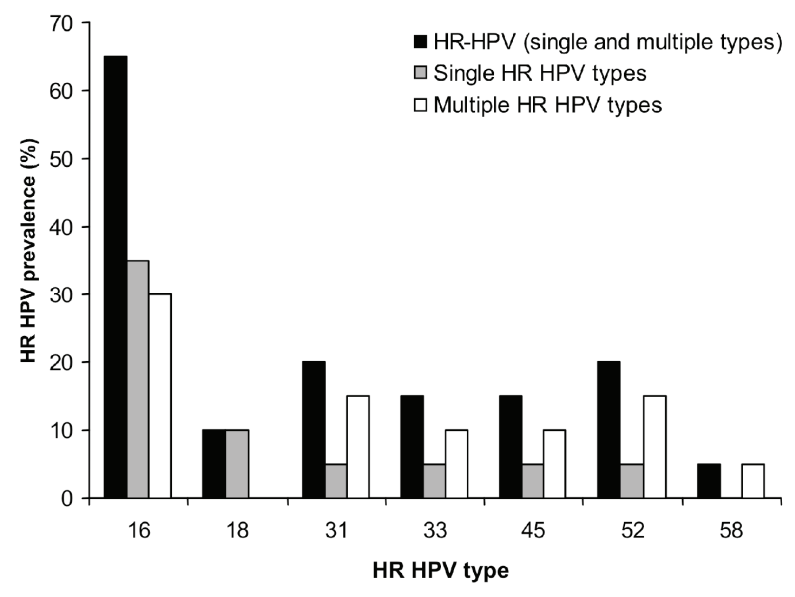

Figure 1. Overview of HR HPV type distribution in the total number of positive cases. HR HPV genotype distribution in order of predominance: HPV $16(n=13 ; 65 \%)$, HPV $31(n=4 ; 20 \%)$, HPV 52 ( $=4 ; 20 \%)$, HPV 33 ( $=3 ; 15 \%)$, HPV $45(\mathrm{n}=3$; $15 \%)$, HPV $18(\mathrm{n}=2 ; 10 \%)$, HPV $58(\mathrm{n}=1 ; 5 \%)$. Single HR HPV type distribution: HPV $16(\mathrm{n}=7 ; 35 \%)$, HPV $18(\mathrm{n}=2$; $10 \%)$, HPV $31(\mathrm{n}=1 ; 5 \%)$, HPV $33(\mathrm{n}=1 ; 5 \%)$, HPV $45(\mathrm{n}=1$; $5 \%)$, HPV $52(\mathrm{n}=1 ; 5 \%)$. Multiple HR HPV type distribution: HPV $16(\mathrm{n}=6 ; 30 \%)$, HPV $31(\mathrm{n}=3 ; 15 \%)$, HPV $52(\mathrm{n}=3$; $15 \%)$, HPV $33(\mathrm{n}=2 ; 10 \%)$, HPV $45(\mathrm{n}=2 ; 10 \%)$, HPV $58(\mathrm{n}=$ $1 ; 5 \%)$.

Figure 1), confirming that, as suggested, HPV16 is the most persistent and aggressive HR HPV type [17] and is able to promote secondary infections or co-infections with other genotypes [11]. Moreover, the inmates with LSIL/HSIL status showed a significantly higher prevalence of multiple HPV types (60\% vs. $1.2 \%$; p < 0.001$)$ respect to women with normal/ASCUS Pap smear (Table 2).

\section{DISCUSSION AND CONCLUSIONS}

Although the main objective of our study was to assess the validity of the HPV DNA test in a high-risk population, our program was designed also to train the participant inmates about the value of cervical cancer prevention, because only a very low percentage of the incarcerated women has attended for cytological Pap-test screening previously. The number of participants to our study out of the total prisoners (approximately 37\%) revealed a general interest to the prevention strategy.

The results of our screening appear to confirm the role of the risk factors taken into account in our study, which characterize the prison population, on the development of higher grade lesions. In fact, although the number of preneoplastic lesions diagnosed by our intervention was comparable to those resulting from larger screenings on the general populations $[11,12]$, the increased percentage of high grade lesions among the inmates confirm the 
Table 2. Association between the sociodemographic characteristics, sexual and health behaviours and the HPV status in the jail inmates.

\begin{tabular}{|c|c|c|c|c|}
\hline Category & Subjects total no & HPVDNA + no (\%) & OR $(95 \% \mathrm{CI})$ & $P$ for trend (chi square) \\
\hline \multicolumn{4}{|c|}{ Age } & 0.0046 \\
\hline$<26$ years & 12 & $6(50)$ & Reference & \\
\hline $26-35$ years & 25 & $4(16)$ & $0.19(0.04-0.90)$ & \\
\hline $36-45$ years & 42 & $9(21.4)$ & $0.273(0.07-1.05)$ & \\
\hline$>45$ years & 19 & 0 & - & \\
\hline \multicolumn{4}{|c|}{ Race/ethnicity } & 0.21 \\
\hline White & 74 & $16(21.6)$ & Reference & \\
\hline Latino/Hispanic & 11 & $2(18.1)$ & $0.71(0.14-3.58)$ & \\
\hline African & 13 & $1(7.7)$ & $0.35(0.04-2.99)$ & \\
\hline \multicolumn{4}{|c|}{ Marital status } & 0.96 \\
\hline Unmarried without current male partner & 30 & $6(20)$ & $1.25(0.37-4.18)$ & \\
\hline Unmarried with current male partner & 8 & $2(25)$ & $1.66(0.27-10.02)$ & \\
\hline Married & 42 & $7(16.7)$ & Reference & \\
\hline Widowed & 8 & $2(25)$ & $1.66(0.27-10.02)$ & \\
\hline Separated-divorced & 10 & $2(20)$ & $1.25(0.21-7.18)$ & \\
\hline \multicolumn{4}{|c|}{ Lifetime no of sex partners } & 0.033 \\
\hline $0-1$ & 24 & $3(12.5)$ & $0.83(0.18-3.68)$ & \\
\hline $2-4$ & 41 & $6(14.6)$ & Reference & \\
\hline $5-9$ & 21 & $5(23.8)$ & $1.82(0.48-6.86)$ & \\
\hline Over 10 & 12 & $5(41.6)$ & $4.16(0.98-17.54)$ & \\
\hline \multicolumn{4}{|c|}{ Age of first sexual intercourse } & 0.34 \\
\hline$<15$ years & 26 & $7(26.9)$ & $2.00(0.65-6.15)$ & \\
\hline $15-19$ years & 58 & $9(15.5)$ & Reference & \\
\hline$>19$ years & 11 & $2(18.1)$ & $1.21(0.22-6.55)$ & \\
\hline \multicolumn{4}{|c|}{ Oral intercourse } & 0.34 \\
\hline Never & 64 & $14(21.8)$ & Reference & \\
\hline Ever & 34 & $5(14.7)$ & $0.61(0.20-1.88)$ & \\
\hline \multicolumn{4}{|c|}{ Anal intercourse } & 0.99 \\
\hline Never & 81 & $16(19.7)$ & Reference & \\
\hline Ever & 17 & $3(17.6)$ & $0.87(0.22-3.39)$ & \\
\hline \multicolumn{4}{|c|}{ Tobacco consumption } & 0.60 \\
\hline Non smokers & 23 & $5(21.7)$ & Reference & \\
\hline 1-10 cigarettes & 24 & $6(25)$ & $1.2(0.31-4.65)$ & \\
\hline$>10$ cigarettes & 51 & $8(15.6)$ & $0.67(0.19-2.32)$ & \\
\hline \multicolumn{4}{|c|}{ Alcohol consumption } & 0.65 \\
\hline Never & 67 & $14(20.8)$ & Reference & \\
\hline Mild & 23 & $3(13.0)$ & $0.56(0.14-2.18)$ & \\
\hline Abuse & 8 & $2(25)$ & $1.26(0.22-6.94)$ & \\
\hline \multicolumn{4}{|c|}{ Condom use } & 0.57 \\
\hline Frequent & 20 & $3(15)$ & Reference & \\
\hline Infrequent or never & 78 & $16(20.5)$ & $1.46(0.38-5.61)$ & \\
\hline \multicolumn{4}{|c|}{ Pap smear during the past 3 years } & 0.51 \\
\hline Yes & 15 & $2(13.6)$ & Reference & \\
\hline No & 83 & $17(20.4)$ & $1.67(0.34-8.13)$ & \\
\hline
\end{tabular}


Table 3. Detection of HR-HPV DNA and accordance with cervical cytology in the inmates attending for the screening.

\begin{tabular}{lccccc}
\hline \multicolumn{1}{c}{ Characteristics } & $\begin{array}{c}\text { Overall } \\
\text { no }=98\end{array}$ & $\begin{array}{c}\text { Normal/ASCUS Pap } \\
\text { smear no }=86\end{array}$ & $\begin{array}{c}\text { LSIL/HSIL Pap smear } \\
\text { no }=5\end{array}$ & Unsatisfactory no $=7$ & $P$ value \\
\hline $\begin{array}{l}\text { HR-HPV Positive } \\
\begin{array}{l}\text { Prevalence of multiple HPV } \\
\text { types }\end{array}\end{array}$ & $19(19.4)$ & $14(16.3)$ & $5(100)^{*}$ & 0 & $<0.001$ \\
\hline
\end{tabular}

$P$ values are from Fisher's exact test; ASCUS, atypical squamous cells of undetermined significance; LSIL, low grade squamous intra-epithelial lesions; HSIL, high grande squamous intraepithelial lesions; * Pap smear: 1 LSIL, 4 HSIL.

validity of the risk factors analyzed through our questionnaire.

Moreover, it is well know that most HPV infections spontaneously regress: however, if the infection is persistent, the risk of cervical cancer substantially increases [18]. In natural or organized screening programs, about $80 \%$ of the detected low grade lesions spontaneously regressed [18,19], while in a population as the jail inmates that never attended to a screening program or that had not more than a Pap test during the life the lesions are believed to persist and progress to high grade.

Our study was designed evaluating all the cytological scrapings after HR-HPV testing and our results are in accordance with those obtained by the experimental arm of the New Technologies for Cervical Cancer (NTCC) [12]. Since in HPV DNA by HC2 screening strategies it is possible to increase the length of follow up respect to Pap-test based programs (3-5 years if HPV DNA test is negative twice) [20], our approach will be very useful for incarcerated women which do not have the opportunity or the social and cultural environment to receive preventive care.

The results on the distribution of the HR-HPV genotypes among the inmates revealed the much higher prevalence of HPV16 compared to the other types in either single or multiple infections, as expected [11,17]. It is currently known that more than $40 \%$ of HR HPV positive cases display multiple viral types [21], although the possible impact of these co-infections on the progression of cervical malignancies has not been determined yet. It is also well recognized that HPV16 represents the predominant genotype [19]. In contrast, the very low percentage of cases positive for HPV18 $(10 \%)$ in our population is somehow surprising, although Clifford et al. have reported heterogeneity in the prevalence of HPV18 in the general population from 11 countries [22]. However, it is known that HPV18 is under-represented in high grade lesions at the time of diagnosis and that the HPV18 associated lesions rapidly progress [23].

We found a much higher rate of unsatisfactory Papsmears $(7.1 \%)$ compared to that reported by Prandi et al. $(1.99 \%)$ in a screened population in Italy [24], possibly due to the more frequent occurrence of vaginal/cervical infections in inmate women. Because one out of the
7 unsatisfactory cytological tests was HR- HPV positive, we may conclude that HPV DNA testing allows to do not repeat an unsatisfactory cervical sample [20], further assessing the value of the addition of HPV DNA testing for screening of a high-risk population.

Finally, in groups of women do not attending to cervical cancer screenings, such as the population studied in this program, the potential benefit of HPV vaccines are enormous. In fact, it is now well recognized that important additional effects of the vaccines are the cross protections against infections and diseases caused by 16/18 related HPV types, specially against HPV 31 and HPV45, which are the other genotypes causally attributed to cervical cancer [25].

\section{ACKNOWLEDGEMENTS}

This work was partially supported by grants from MIUR, from Ministero della Salute and from Italian Association for Cancer Research (AIRC), Italy. The Digene Italia kindly provided STM collection media and kits for HPV High Risk detection. The Innogenetics kindly provided INNO-LiPA kits for HPV genotyping.

\section{REFERENCES}

[1] Proca, D.M., Rofagha, S. and Keyhani-Rofagha, S. (2006) High grade squamous intraepithelial lesion in inmates from Ohio: Cervical screening and biopsy follow-up. CytoJournal, 3(10), 15.

[2] Binswanger, I.A., White, M.C., Pérez-Stable, E.J., Goldenson, J. and Tulsky, J.P. (2005) Cancer screening among jail inmates: Frequency, knowledge and willingness. American Journal of Public Health, 95(10), 1781-1787.

[3] Magee, C.G., Hult, J.R., Turalba, R. and McMillan, S. (2005) Preventive care for women in prison: A qualitative community health assessment of the Papanicolaou test and follow-up treatment at a California state women's prison. American Journal of Public Health, 95(10), 17121717.

[4] Martin, R.E., Hislop, T.G., Moravan, V., Grams, G.D. and Calam, B. (2008) Three-year follow-up study of women who participated in a cervical cancer screening intervention while in prison. Canadian Journal of Public Health, 99(44), 262-266.

[5] Martin, R.E., Hislop, T.G., Grams, G., Calam, E., Jones, 
E. and Moravan, V. (2004) Evaluation of a cervical cancer screening intervention for prison inmates. Canadian Journal of Public Health, 95(4), 285-289.

[6] Benard, V.B., Johnson, C.J., Thompson, T.D., et al. (2008) Examining the association between socioeconomic status and potential human human papillomavirus associated cancer. Cancer, 113(Suppl. 10), 2910-2918.

[7] Appleby, P., Beral, V., Berrington de González, A., et al. (2007) Cervical cancer and hormonal contraceptives: Collaborative reanalysis of individual data for 16,573 women with cervical cancer and 35,509 women without cervical cancer from 24 epidemiological studies. Lancet, 370(9599), 1609-1621.

[8] Burd, E.M. (2003) Human papillomavirus and cervical cancer. Clinical Microbiology Reviews, 16(1), 1-17.

[9] Kapeu, A.S., Luostarinen, T., Jellum, E., et al. (2008) Is smoking an independent risk factor for invasive cervical cancer? A nested case-control study within nordic biobanks. American Journal of Epidemiology, 169(4), 480488.

[10] Winer, R.L., Hughes, J.P., Feng, Q., O’Reilly, et al. (2006) Condom use and the risk of genital human papillomavirus infection in young women. New England Journal of Medicine, 354(25), 2645-2654.

[11] Kiaer, S.K., Breugelmans, G., Munk, C., Junge, J., Watson, M. and Iftner, T. (2008) Population-based prevalence, type- and age-specific distribution of HPV in women before introduction of an HPV-vaccination program in Denmark. International Journal of Cancer, $\mathbf{1 2 3}$ (8), 1864-1870.

[12] Ronco, G., Giorgi-Rossi, P., Carozzi, F., et al. (2008) Results at recruitment from a randomized controlled trial comparing human papillomavirus testing alone with conventional cytology as the primary cervical cancer screening test. Journal of the National Cancer Institute, 100(7), 492-501.

[13] Hibbitts, S., Jones, J., Powell, N., Dallimore, N., et al. (2008) Human papillomavirus prevalence in women attending routine cervical screening in South Wales, UK: A cross-sectional study. British Journal of Cancer, 99(11), 1929-1933.

[14] Burchell, A.N., Winer, R.L., de Sanjosè, S., Franco, E.L. (2006) Chapter 6: Epidemiology and transmission dynamics of genital HPV infection. Vaccine, 24(S3), 52-61.

[15] Ronco, G., Giorgi-Rossi, P., Carozzi, F., et al. (2010) New Technologies for Cervical Cancer screening (NTCC) Working Group. Efficacy of human papillomavirus testing for the detection of invasive cervical cancers and cervical intraepithelial neoplasia: A randomised con- trolled trial. Lancet Oncology, 11(3), 249-257.

[16] Cuzick, J., Clavel, C., Petry, K.U., et al. (2006) Overview od European and North American studies on HPV testing in primary cervical cancer screening. International Journal of Cancer, 119(5), 1095-1101.

[17] Smith, J.S., Lindsay, L., Hoots, B., et al. (2007) Human papillomavirus type distribution in invasive cervical cancer and high-grade cervical lesions: A meta-analysis update. International Journal of Cancer, 121(3), 621632.

[18] Woodman, C.B.J., Collins, S., Rollason, T.P., et al. (2003) Human papillomavirus type 18 and rapidly progressing cervical intraepithelial neoplasia. Lancet, 361(9351), 4043.

[19] Bosch, F.X., Burchell, A.N., Schiffman, M., et al. (2008) Epidemiology and natural history of human papillomavirus infections and type-specific implications in cervical neoplasia. Vaccine, 26(S10), K1-K16.

[20] Zhao, C. and Austin, R.M. (2009) High-risk human papillomavirus DNA test results are useful for disease risk stratification in women with unsatisfactory liquid-based cytology pap test results. Journal of Lower Genital Tract Disease, 13(2), 79-84.

[21] Mendez, F., Munoz, N., Posso, H., et al. (2005) Cervical coinfection with human papillomavirus types and possible implicaqtions for the prevention of cervical cancer by HPV vaccines. Journal of Infectious Diseases, 192(7), 1158-1165.

[22] Clifford, G.M., Gallus, S., Herrero, R., et al. (2005) Worldwide distribution of human papillomavirus types in cytologically normal women in the International Agency for Research on Cancer HPV prevalence surveys: A pooled analysis. Lancet, 366(9490), 991-998.

[23] Clifford, G.M., Rana, R.K., Franceschi, S., Smith, J.S., Gough, G. and Pimenta, J.M. (2005) Human papillomavirus genotype distribution in low-grade cervical lesions: comparison by geographic region and with cervical cancer. Cancer Epidemiology Biomarkers \& Prevention, 14(5), 1157-1164.

[24] Prandi, S., Beccati, D., de Aloysio, G, et al. (2006) Applicability of the Bethesda system 2001 to a public health setting. Cancer, 108(5), 271-276.

[25] Paavonen, J., Naud, P., Salmerón, J., et al. (2009) Efficacy of human papillomavirus (HPV)-16/18 AS04-adjuvanted vaccine against cervical infection and precancer caused by oncogenic HPV types (PATRICIA): Final analysis of a double-blind, randomised study in young women. Lancet, 274(9686), 301-314. 